\section{Case Reports in Neurology}

Rep Neurol 2018:10:1-6

\title{
Microsurgical Treatment of Intraventricular Cavernoma with Prior Planning Neuroendoscopy
}

\author{
Flavio Nigri Jucilana dos Santos Viana \\ Pedro Henrique da Costa Ferreira Pinto Elington Lannes Simões \\ Carlos Roberto Telles Ribeiro \\ Pedro Ernesto University Hospital, University of State of Rio de Janeiro, \\ Rio de Janeiro, Brazil
}

\section{Keywords}

Cavernous angioma $\cdot$ Vascular malformation $\cdot$ Neuroendoscopy $\cdot$ Microsurgery

\begin{abstract}
Microsurgery remains the gold standard treatment for intraventricular lesions, but it is not without limitations. The cerebral ventricles approach is considered a challenge for neurosurgeons because of their deep location and their intimate association with critical areas of the brain. It has been shown that direct endoscopic view is superior to magnetic resonance imaging (MRI) in identifying intraventricular structures and lesions. Also, during neuroendoscopy, there is no cerebrospinal fluid leak causing brain collapse as seen in microsurgery. Different surgical strategies should be shared and may improve and facilitate intraventricular lesions resection. Herein, a case of a successful microsurgical cavernoma resection with prior ventriculoscopy is described. A 28-year-old woman was admitted with intense holocranial headache. A mild stiff neck was observed. MRI showed a 3-cm lesion with heterogeneous signal intensity and no contrast enhancement suggestive of cavernoma. Initially, a ventriculoscopy was done to inspect the lesion and the surrounding ventricular structures. After that, a conversion technique from endoscopy to microsurgery was performed. The initial corticectomy was extended and the endoscope pathway was followed into the ventricular cavity. Then, the cavernoma was completely removed by microsurgical technique. No complications were observed. Control MRI showed total tumour removal. The patient remained asympto-
\end{abstract}


matic with no recurrence after 1 year. This case illustrates a successful prior endoscopic approach followed by microsurgery as an alternative to a direct microsurgical approach for intraventricular cavernoma. A previous direct endoscopic view of the lesion and its relation with intraventricular structures may ensure a safe and complete resection by microsurgery.

(C) 2018 The Author(s)

Published by S. Karger AG, Basel

\section{Introduction}

Cerebral cavernous malformations, also known as cavernous angiomas, cavernomas, or cryptic vascular malformations, are rare venous capillary bed abnormalities [1]. Cavernomas comprise $5-13 \%$ of all cerebrovascular malformations [2]. Intraventricular cavernomas (IVCs) are rare and account for $2.5-10.8 \%$ of cerebral cavernomas [1]. The lateral ventricles are the most frequent site, followed by the third and fourth ventricles [3]. Microsurgery remains the gold standard for the treatment of intraventricular lesions, but it is not without limitations [4]. The ventricular region approach is considered a challenge for neurosurgeons because of the deep location and the intimate association of the cerebral ventricles with critical areas of the brain [5]. During a microsurgical approach, the drainage of cerebrospinal fluid may collapse ventricles and complicate the visualization of the surrounding neurovascular structures. It has also been shown that direct endoscopic view is superior to magnetic resonance imaging (MRI) in identifying intraventricular structures and lesions [6]. Experience gained with different surgical strategies should be shared to improve and facilitate intraventricular lesions resection. Because of that, herein, a case of a successful microsurgical resection of an IVC with prior ventriculoscopy view is reported.

\section{Case Report}

A 28-year-old woman was admitted complaining of intense holocranial headache. She had suffered from 2 previous episodes of sudden headache with vomiting in the last $24 \mathrm{~h}$. No other symptoms were reported. A mild stiff neck was observed. Axial brain computed tomography (CT) revealed a hyperdense lesion located in the right lateral ventricle. MRI showed a 3-cm lesion with heterogeneous signal intensity and no contrast enhancement suggestive of cavernoma (Fig. 1). The surgical treatment was considered because of a new intraventricular haemorrhage risk. The benefits and pitfalls of the surgery were discussed with the family. We first approached the patient performing a ventriculoscopy (Gaab endoscope, Karl Storz, Tuttlingen, Germany) through a right-side Kocher's point burr hole. After the inspection of the cavernoma and the surrounding ventricular structures (Fig. 2), the Gaab endoscope was withdrawn and the cortical trajectory temporarily closed with a haemostatic absorbable gelatin sponge (Gelfoam ${ }^{\circledR}$, Pfizer, Kalamazoo, MI, USA). There was no attempt to remove or coagulate the lesion during the endoscopy because of the risk of uncontrolled bleeding. The initial $5-\mathrm{cm}$ coronal skin incision for the endoscopy was enlarged to $10 \mathrm{~cm}$, and a $5-\mathrm{cm}$ diameter craniotomy was performed according to previously described conversion technique [7]. The initial corticectomy was extended and the endoscope pathway was followed with brain spatulas in order to reach the ventricular cavity. Then, the cavernoma was completely removed by a microsurgical technique. An external ventricular drainage catheter was left in place and maintained closed for $48 \mathrm{~h}$. No hydrocephalus was 
Nigri et al.: Microsurgical Treatment of Intraventricular Cavernoma with Prior Planning Neuroendoscopy

observed. The patient was discharged without neurologic disorders on the fifth postoperative day. She remained asymptomatic with no recurrence after 1 year (Fig. 1).

\section{Discussion}

Most IVCs manifest as obstructed hydrocephalus. Convulsions are the second most common symptom [8]. Other symptoms reported are headaches, memory deficit, pituitary dysfunction, nausea, vomiting, cranial nerve deficit and focal mass effect causing neurologic deficits [1]. Our patient's symptoms were probably caused by a small ventricular bleeding characterized by the clot observed during ventriculoscopy (Fig. 2). On imaging, IVC may show a similar appearance to that of intraparenchymal cavernoma. On CT, they are intrinsically hyperdense on unenhanced exams with specks of calcification. Following intravenous contrast, enhancement can vary from none to avid. MRI demonstrates a well-defined mass with heterogeneous signal intensity on both T1- and T2-weighted sequences. The hypointense areas correlate with areas of calcification and fibrosis, while the hyperintense areas correlate with areas of metheamoglobin. These lesions also demonstrate a hypointense peripheral rim on T2-weighted images [9]. Despite all technological imaging improvements, the precise relationship between the lesion and the ventricular structures and the clot identification, in our case, was best observed by endoscopic view. The microsurgical approach is the more advocated treatment for IVC $[3,10,11]$. Modern microsurgical techniques guarantee a safe and complete resection of IVC, but a high rate of postoperative neurological deficits is still associated with these procedures [3]. Despite the increasing role of neuroendoscopy in the treatment of intraventricular lesions, for IVC, the use of endoscopy has been used to confirm the diagnosis under direct view and to establish surgical alternatives [2]. However, there are reports of complete pure endoscopic IVC resection [2, 12]. In our case, there was no attempt at performing pure endoscopic cavernoma resection because of uncontrolled bleeding risk that might increase morbidity. Two main advantages in performing microsurgery with prior planning neuroendoscopy were observed in this case. First, the inspection of ventricular structures and their relations with the cavernoma inside the fully filled ventricles. Cerebrospinal fluid leak during the microsurgical approach normally collapses ventricles and distorts the original anatomy. Then, it was possible to clearly identify cavernoma implantation on the septum pellucidum and the free surrounding critical structures (Fig. 2). Second, having a direct access to the ventricular cavity through the endoscopic pathway results in minimal brain manipulation. The decision to start the procedure with a small incision and a single burr hole was done to optimize the cranial references for endoscopy.

\section{Conclusion}

A prior endoscopic approach may be helpful because it creates a path for the ventricular cavity, minimizing brain parenchyma manipulation and damage, besides supporting the preservation of eloquent intraventricular structures by direct previous visualization. This successful prior endoscopic approach followed by microsurgery may be seen as an alternative to a direct microsurgical approach for IVC. 


\section{Case Reports in Neurology}

\section{Statement of Ethics}

The patient consented to the publication.

\section{Disclosure Statement}

The authors have no personal, financial or institutional interest in any of the drugs, materials or devices mentioned in the article.

\section{References}

1 Winslow N, Abode-Iyamah K, Flouty O, Park B, Kirby P, Howard M 3rd: Intraventricular foramen of Monro cavernous malformation. J Clin Neurosci 2015;22:1690-1693.

2 Prat R, Galeano I: Endoscopic resection of cavernoma of foramen of Monro in a patient with familial multiple cavernomatosis. Clin Neurol Neurosurg 2008;110:834-837.

-3 Carrasco R, Pedrosa M, Pascual JM, Navas M, Liberal R, Sola RG: Cavernous angiomas of the lateral ventricles. Acta Neurochir (Wien) 2009;151:149-154

-4 Barber SM, Rangel-Castilla L, Baskin D: Neuroendoscopic resection of intraventricular tumors: a systematic outcomes analysis. Minim Invasive Surg 2013;2013:898753.

5 Yasargil MG, Abdulrauf SI: Surgery of intraventricular tumors. Neurosurgery 2008;62(suppl):10291040.

6 Abderrahmen K, Aouidj ML, Kallel J, Zammel I, Khaldi MM: Hydrocephalus due to non tumoral stenosis of foramens of Monro: report of four cases (in French). Neurochirurgie 2008;54:72-78.

-7 Pinto PHC, Nigri F, Gobbi GN, Caparelli-Daquer EM: Conversion technique from neuroendoscopy to microsurgery in ventricular tumors: technical note. Surg Neurol Int 2016;7:S785-S789.

-8 Song WZ, Mao BY, Hu YH, Liu YH, Sun H, Mao Q: Intraventricular vascular malformations mimicking tumors: case reports and review of the literature. J Neurol Sci 2008;266:63-69.

9 Nguyen J, Kanekar S, Purayidom AS: Intraventricular cavernoma. Appl Radiol 2010;39:54-58.

10 Kivelev J, Niemelä M, Kivisaari R, Hernesniemi J: Intraventricular cerebral cavernomas: a series of 12 patients and review of the literature. J Neurosurg 2010;112:140-149.

11 Muzumdar D, Avinash KM, Ramdasi R: Cavernoma of the septum pellucidum in the region of foramen of Monro. Neurol India 2015;63:68-71.

$\$ 12$ Giannetti AV: Purely neuroendoscopic resection of an intraventricular cavernous angioma: case report. J Neurol Surg A Cent Eur Neurosurg 2013;74:47-50. 


\section{Case Reports in Neurology}

\begin{tabular}{|c|c|}
\hline ase $\mathrm{R}$ & \\
\hline DOI: $10.1159 / 000485374$ & $\begin{array}{l}\text { ( ) } 2018 \text { The Author(s). Published by S. Karger AG, Basel } \\
\text { www.karger.com/crn }\end{array}$ \\
\hline
\end{tabular}

Nigri et al.: Microsurgical Treatment of Intraventricular Cavernoma with Prior Planning Neuroendoscopy
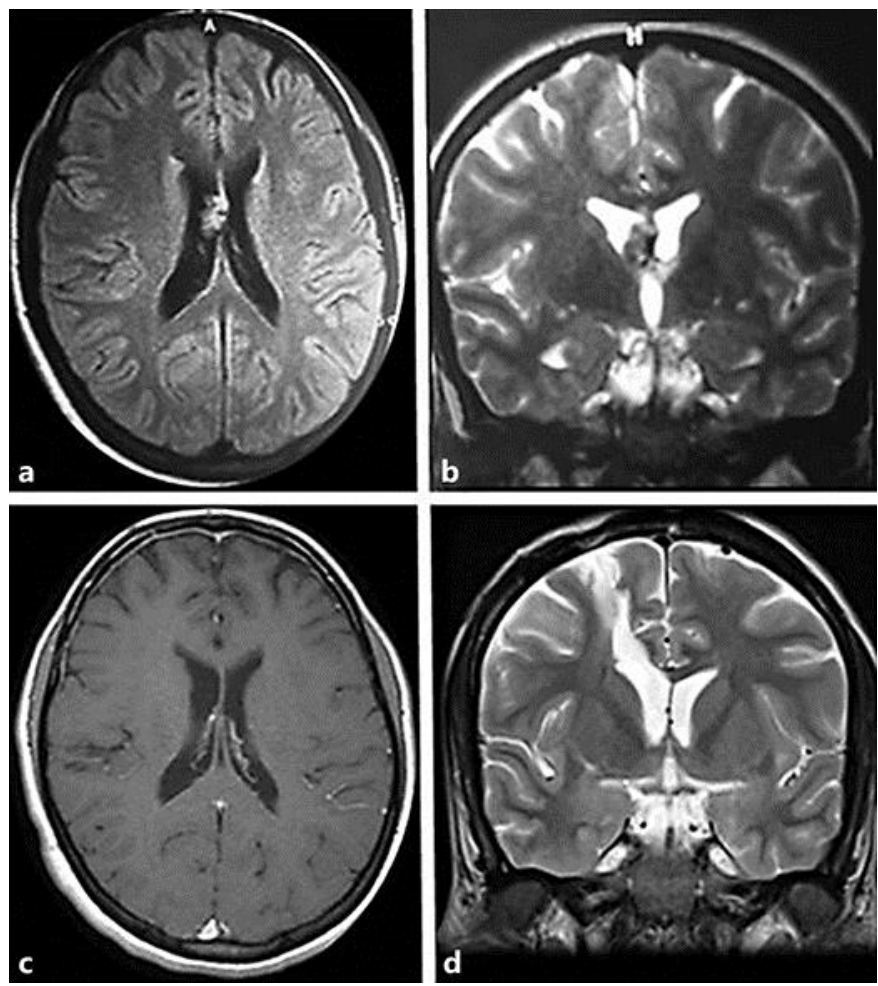

Fig. 1. a, b MRI axial FLAIR image and coronal T2-weighted image showing a heterogeneous signal intensity lesion attached to the septum pellucidum. c, d Postoperative MRI axial T1-weighted and coronal T2weighted images showing total lesion removal. 


\section{Case Reports in Neurology}

\begin{tabular}{l|l}
\hline Case Rep Neurol 2018;10:1-6 \\
\hline DOI: 10.1159/000485374 & $\begin{array}{l}\text { (C) 2018 The Author(s). Published by S. Karger AG, Basel } \\
\text { www.karger.com/crn }\end{array}$ \\
\hline
\end{tabular}

Nigri et al.: Microsurgical Treatment of Intraventricular Cavernoma with Prior Planning Neuroendoscopy
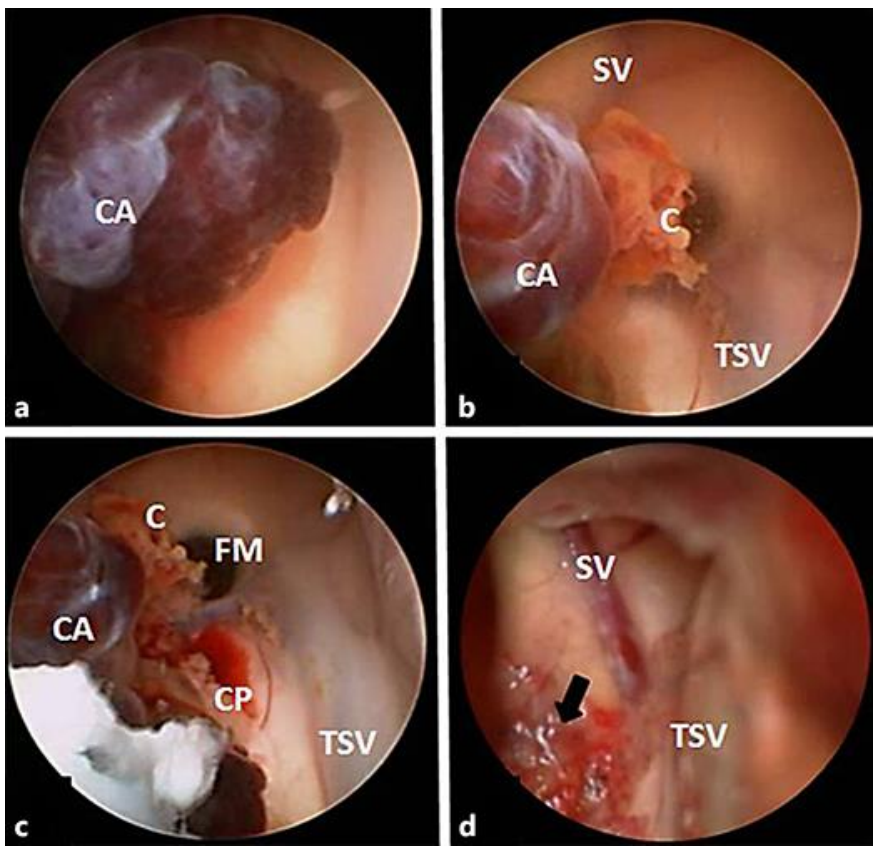

Fig. 2. a Neuroendoscopic view of the CA. b, c CA relationship to adjacent anatomical structures. $\mathbf{d}$ Microsurgical view of the septum pellucidum after lesion removal (arrow). CA, cavernous angioma; SV, septal vein; C, clot; TSV, thalamostriate vein; CP, choroid plexus; FM, foramen of Monro. 